\title{
Solid-State Synthesis and Thermoelectric Properties of Tetrahedrites $\mathrm{Cu}_{12} \mathbf{S b}_{4-y} \mathbf{B i}_{y} \mathbf{S}_{13}$ Sung-Gyu Kwak, Ji-Hee Pi, Go-Eun Lee, and Il-Ho Kim* \\ Department of Materials Science and Engineering, Korea National University of Transportation, Chungju 27469, Republic of Korea
}

\begin{abstract}
Tetrahedrite has low lattice thermal conductivity because of the lone-pair electrons of Sb, which cause the $\mathrm{Cu}$ atoms to vibrate at a low frequency and high amplitude. The synthesis of tetrahedrite compounds by conventional melting methods requires a long-time reaction and annealing. However, a homogeneous and solid-state synthesis can be conducted in a short time using mechanical alloying (MA) because the volatilization of the constituent elements is inhibited and a subsequent heat treatment is not necessary. In this study, Bi-doped tetrahedrites $\mathrm{Cu}_{12} \mathrm{Sb}_{4-y} \mathrm{Bi}_{y} \mathrm{~S}_{13}(y=0-0.4)$ were prepared by MA and hot pressing. X-ray diffraction analyses revealed that all specimens consisted of single-phase tetrahedrite. However, with increasing $\mathrm{Bi}$ content, skinnerite $\mathrm{Cu}_{3} \mathrm{SbS}_{3}$ was detected. The electrical conductivity increased and the Seebeck coefficient deceased with increasing Bi content as result of the substitution of $\mathrm{Bi}$ at $\mathrm{Sb}$ sites. In addition, the thermal conductivity increased as the Bi content increased because of the increase in electronic thermal conductivity. A high dimensionless figure of merit of 0.88 was obtained at $723 \mathrm{~K}$ for $\mathrm{Cu}_{12} \mathrm{Sb}_{3.9} \mathrm{Bi}_{0.1} \mathrm{~S}_{13}$.
\end{abstract}

(Received January 6, 2020; Accepted February 3, 2020)

Keywords: thermoelectric, tetrahedrite, mechanical alloying, hot pressing

\section{INTRODUCTION}

Tetrahedrite is an abundant natural material in the earth and has recently attracted considerable attention as a $p$-type thermoelectric material for mid-temperature applications. Synthetic tetrahedrite $\left(\mathrm{Cu}_{12} \mathrm{Sb}_{4} \mathrm{~S}_{13}\right)$ exhibits good thermoelectric performance near $723 \mathrm{~K}$ [1,2]. $\mathrm{Cu}_{12} \mathrm{Sb}_{4} \mathrm{~S}_{13}$ has a complex crystal structure with 58 atoms arranged in a highly symmetric cubic unit cell composed of $\mathrm{Cu}^{\mathrm{I}} \mathrm{S}_{4}$ tetrahedra, $\mathrm{Cu}^{\mathrm{II}} \mathrm{S}_{3}$ triangles, and $\mathrm{SbS}_{3}$ trigonal pyramids [3]. The most prominent characteristic of tetrahedrite is its low thermal conductivity. Because of the active lone-pair electrons of the $\mathrm{Sb}$ atoms, $\mathrm{Cu}^{\mathrm{II}}$ atoms in a plane $\mathrm{S}$ triangle induce low lattice thermal conductivity by anharmonic oscillation with low frequency and high amplitude [4-6]. Thermoelectric conversion efficiency is evaluated using a dimensionless figure of merit $(Z T)$ defined as $Z T=\alpha^{2} \sigma \kappa^{-1} T$, where $\alpha, \sigma, \kappa$, and $T$ are the Seebeck coefficient, electrical conductivity, thermal conductivity, and absolute temperature, respectively.

- 곽성규: 석사과정, 피지희 - 이고은: 박사과정, 김일호: 교수

*Corresponding Author: Il-Ho Kim

[Tel: +82-43-841-5387, E-mail: ihkim@ut.ac.kr]

Copyright (c) The Korean Institute of Metals and Materials
Good thermoelectric materials need to have a high Seebeck coefficient, high electrical conductivity, and low thermal conductivity, however, the Seebeck coefficient and electrical conductivity have a trade-off relationship to the power factor. In general, the power factor can be improved by optimizing the carrier concentration through doping.

Most studies on tetrahedrites have focused on the substitution of transition elements ( $\mathrm{Zn}, \mathrm{Fe}, \mathrm{Ni}$, etc.) for $\mathrm{Cu}$ sites [7-9], but few studies have reported on the effects of doping for $\mathrm{Sb}$ sites. In this approach, the Sb site of the natural mineral tetrahedrite is partially replaced by $\mathrm{As}, \mathrm{Bi}$, or $\mathrm{Te}$ atoms. Studies on the substitution of $\mathrm{Sb}$ sites in synthetic tetrahedrite have been reported. Kumar et al. [10] reported on Bi-doped $\mathrm{Cu}_{12} \mathrm{Sb}_{4-y} \mathrm{Bi}_{y} \mathrm{~S}_{13}$ prepared by encapsulated melting and hot pressing (HP). As the amount of Bi increased, both the carrier concentration (electrical conductivity) and thermal conductivity decreased. As a result, a $Z T$ of 0.84 was obtained at $673 \mathrm{~K}$ for $\mathrm{Cu}_{12} \mathrm{Sb}_{3.9} \mathrm{Bi}_{0.1} \mathrm{~S}_{13}$. Bouyrie et al. [11] studied Te-doped $\mathrm{Cu}_{12} \mathrm{Sb}_{4-y} \mathrm{Te}_{y} \mathrm{~S}_{13}$ synthesized by encapsulated melting and spark plasma sintering. As the content of $\mathrm{Te}$ increased, the carrier concentration and thermal conductivity decreased, and thus a $Z T$ of 0.8 was achieved at $623 \mathrm{~K}$ for 
$\mathrm{Cu}_{12} \mathrm{Sb}_{3.39} \mathrm{Te}_{0.61} \mathrm{~S}_{13}$.

In general, when tetrahedrite is synthesized using a melting process, sophisticated and slow reactions (heating-holdingcooling) are required because the boiling point $(717.8 \mathrm{~K})$ of $\mathrm{S}$ is considerably lower than the melting point $(1356.6 \mathrm{~K})$ of $\mathrm{Cu}$. In addition, a long-time heat treatment is required for phase transformation and homogenization. In this regard, mechanical alloying (MA) has several advantages over conventional melt-crushing techniques, including the prevention of phase separation and vaporization during melting. MA has been previously employed in the synthesis of nanosized powders. In our previous study, a single tetrahedrite phase was successfully synthesized in a short time using the MA method [12]. In this study, Bi-doped tetrahedrites $\mathrm{Cu}_{12} \mathrm{Sb}_{4-y} \mathrm{Bi}_{y} \mathrm{~S}_{13}$ were prepared by MA and $\mathrm{HP}$, and their thermoelectric properties were examined. By partially substituting $\mathrm{Bi}$ for the $\mathrm{Sb}$ sites of the tetrahedrite, we expected an enhanced power factor and reduced thermal conductivity, and improved thermoelectric performance by optimizing the carrier concentration.

\section{EXPERIMENTAL PROCEDURE}

Bi-doped tetrahedrites $\mathrm{Cu}_{12} \mathrm{Sb}_{4-y} \mathrm{Bi}_{y} \mathrm{~S}_{13}(y=0.1-0.4)$ were synthesized by MA. Cu (purity 99.9\%, < $45 \mu \mathrm{m}$, Kojundo), $\mathrm{Sb}$ (purity 99.999\%, < $150 \mu \mathrm{m}$, Kojundo), Bi (purity 99.999\%, $<180 \mu \mathrm{m}$, Kojundo), and S (purity 99.99\%, < $75 \mu \mathrm{m}$, Kojundo) were weighed to the stoichiometric composition. The mixed powder was charged into a hardened stainlesssteel jar with stainless-steel balls having diameters of $5 \mathrm{~mm}$, where the ball-to-powder weight ratio was 20. MA was performed at $350 \mathrm{rpm}$ for $24 \mathrm{~h}$ in an Ar atmosphere using a planetary mill (Fritsch Pulverisette5). The synthesized powder was loaded into a graphite mold having an inner diameter of $10 \mathrm{~mm}$ and subjected to consolidation using HP at $723 \mathrm{~K}$ for $2 \mathrm{~h}$ under $70 \mathrm{MPa}$ in vacuum. Details of the MA-HP process for the solid-state synthesis of tetrahedrite are described in the previous study [12].

The phases of the MA powders and HP specimens were analyzed using X-ray diffraction (XRD; Bruker D8Advance) with $\mathrm{Cu}-\mathrm{K} \alpha$ radiation $(\lambda=0.15405 \mathrm{~nm})$. The diffraction patterns were measured in the $\theta-2 \theta$ mode $(2 \theta=$ $10-90^{\circ}$ ) with a step size of $0.02^{\circ}$ at a scan speed of $0.4 \mathrm{~s} / \mathrm{step}$.
The fractured surfaces of the HP specimens were observed using scanning electron microscopy (SEM; FEI Quanta400), and elemental analysis was conducted using energydispersive spectrometry (EDS; Bruker Quantax200). The energy levels of the elements were $\mathrm{Cu}-\mathrm{L} \alpha(0.928 \mathrm{eV}), \mathrm{Sb}-\mathrm{L} \alpha$ (3.604 eV), Bi-M $\alpha$ (2.423 eV), and S-K $\alpha(2.309 \mathrm{eV})$. The sintered body was cut into a rectangular parallelepiped of 3 $\times 3 \times 9 \mathrm{~mm}$ to measure the Seebeck coefficient and electrical conductivity. It was then further cut into a disk of $10 \mathrm{~mm}$ (diameter) $\times 1 \mathrm{~mm}$ (thickness) for thermal conductivity measurement. Thermoelectric properties were examined in the temperature range of 323 to $723 \mathrm{~K}$. The Seebeck coefficient and electrical conductivity were measured using the temperature-differential and DC four-probe method in a He atmosphere (Ulvac-Riko ZEM-3). The thermal conductivity was obtained by the laser flash method (UlvacRiko TC-9000H) after thermal diffusivity, specific heat, and density were measured. Finally, the power factor $\left(\mathrm{PF}=\alpha^{2} \sigma\right)$ and the $Z T\left(=\alpha^{2} \sigma \kappa^{-1} T\right)$ were evaluated.

\section{RESULTS AND DISCUSSION}

Figure 1 shows the XRD patterns of $\mathrm{Cu}_{12} \mathrm{Sb}_{4-y} \mathrm{Bi}_{y} \mathrm{~S}_{13}$ synthesized by MA and sintered by HP. The diffraction peaks of all specimens matched the standard diffraction data (PDF\#024-1318, space group $I \overline{4} 3 \mathrm{~m}$ ). However, a small amount of $\mathrm{Cu}_{3} \mathrm{SbS}_{3}$ (skinnerite, PDF\#082-0851, space group

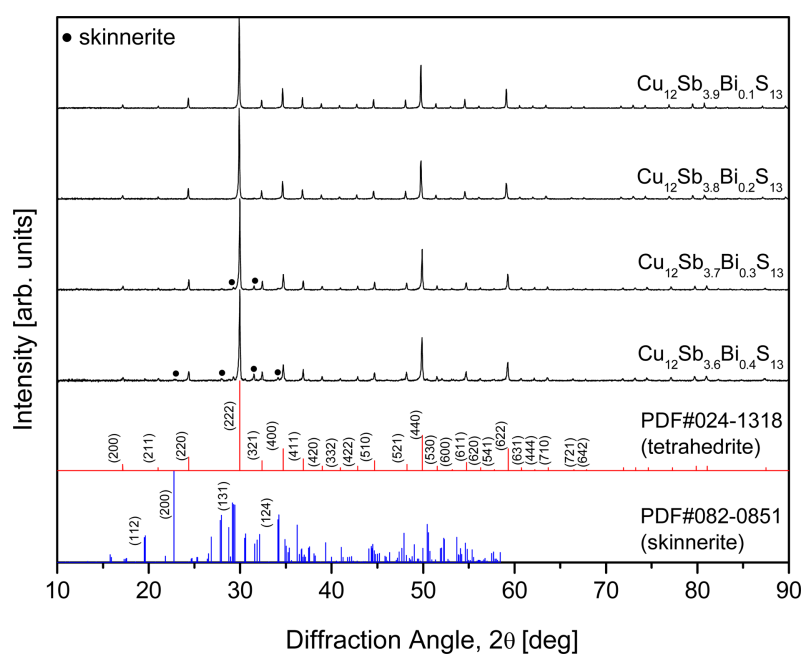

Fig. 1. XRD patterns of $\mathrm{Cu}_{12} \mathrm{Sb}_{4-y} \mathrm{Bi}_{y} \mathrm{~S}_{13}$ tetrahedrites prepared by the MA-HP process. 
Table 1. Chemical compositions and physical properties of $\mathrm{Cu}_{12} \mathrm{Sb}_{4-y} \mathrm{Bi}_{y} \mathrm{~S}_{13}$ at room temperature.

\begin{tabular}{|c|c|c|c|c|}
\hline \multicolumn{2}{|c|}{ Composition } & \multirow{2}{*}{$\begin{array}{c}\text { Relative density } \\
{[\%]}\end{array}$} & \multirow{2}{*}{$\begin{array}{l}\text { Lattice constant } \\
{[\mathrm{nm}]}\end{array}$} & \multirow{2}{*}{$\begin{array}{l}\text { Lorenz number } \\
{\left[10^{-8} \mathrm{~V}^{2} \mathrm{~K}^{-2}\right]}\end{array}$} \\
\hline Nominal & Actual & & & \\
\hline $\mathrm{Cu}_{12} \mathrm{Sb}_{3.9} \mathrm{Bi}_{0.1} \mathrm{~S}_{13}$ & $\mathrm{Cu}_{12.87} \mathrm{Sb}_{5.14} \mathrm{Bi}_{0.14} \mathrm{~S}_{10.85}$ & 97.9 & 1.0333 & 1.76 \\
\hline $\mathrm{Cu}_{12} \mathrm{Sb}_{3.8} \mathrm{Bi}_{0.2} \mathrm{~S}_{13}$ & $\mathrm{Cu}_{13.65} \mathrm{Sb}_{4.41} \mathrm{Bi}_{0.26} \mathrm{~S}_{10.68}$ & 98.9 & 1.0336 & 1.84 \\
\hline $\mathrm{Cu}_{12} \mathrm{Sb}_{3.7} \mathrm{Bi}_{0.3} \mathrm{~S}_{13}$ & $\mathrm{Cu}_{13.84} \mathrm{Sb}_{4.39} \mathrm{Bi}_{0.32} \mathrm{~S}_{10.44}$ & 98.8 & 1.0337 & 1.88 \\
\hline $\mathrm{Cu}_{12} \mathrm{Sb}_{3.6} \mathrm{Bi}_{0.4} \mathrm{~S}_{13}$ & $\mathrm{Cu}_{12.25} \mathrm{Sb}_{3.99} \mathrm{Bi}_{0.45} \mathrm{~S}_{12.30}$ & 99.2 & 1.0331 & 1.82 \\
\hline
\end{tabular}
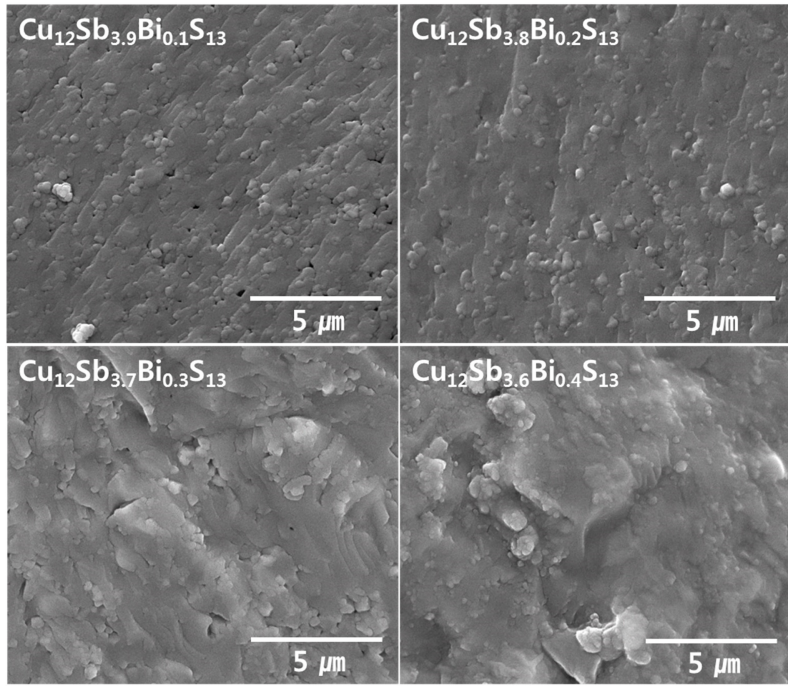

Fig. 2. SEM images of fractured surfaces of $\mathrm{Cu}_{12} \mathrm{Sb}_{4-y} \mathrm{Bi}_{y} \mathrm{~S}_{13}$.

$P 2_{1} / c$ ) was detected for samples with $y \geq 0.3$. Kumar et al.

[10] reported that the formation of impurity phases $\left(\mathrm{Cu}_{3} \mathrm{SbS}_{3}\right.$ and $\mathrm{Cu}_{3} \mathrm{SbS}_{4}$ ) increased as the $\mathrm{Bi}$ content increased. This was because the solubility limit of $\mathrm{Bi}$ in natural mineral tetrahedrite containing $\mathrm{Bi}$ is intrinsically low. Table 1 shows that the lattice constant slightly increased as a result of the $\mathrm{Bi}$ substitution because the ionic radius of $\mathrm{Bi}^{3+}(96 \mathrm{pm})$ is larger than that of $\mathrm{Sb}^{3+}(76 \mathrm{pm})$ [10]. However, for the sample with $y=0.4$, the lattice constant did not increase because the solubility limit was exceeded.

Figure 2 presents SEM images of the fractured surfaces of $\mathrm{Cu}_{12} \mathrm{Sb}_{4-y} \mathrm{Bi}_{y} \mathrm{~S}_{13}$. Densely sintered bodies were obtained with high relative densities of $97.9-99.2 \%$. No significant change was found in the microstructure due to the Bi substitution. Figure 3 shows the EDS elemental maps of the $\mathrm{Cu}_{12} \mathrm{Sb}_{3.9} \mathrm{Bi}_{0.1} \mathrm{~S}_{13}$ from a typical specimen with uniform distribution of constituent elements. Table 1 shows that $\mathrm{Cu}$ and $\mathrm{Sb}$ contents were higher and $\mathrm{S}$ content was lower than the nominal composition. As mentioned in our description of

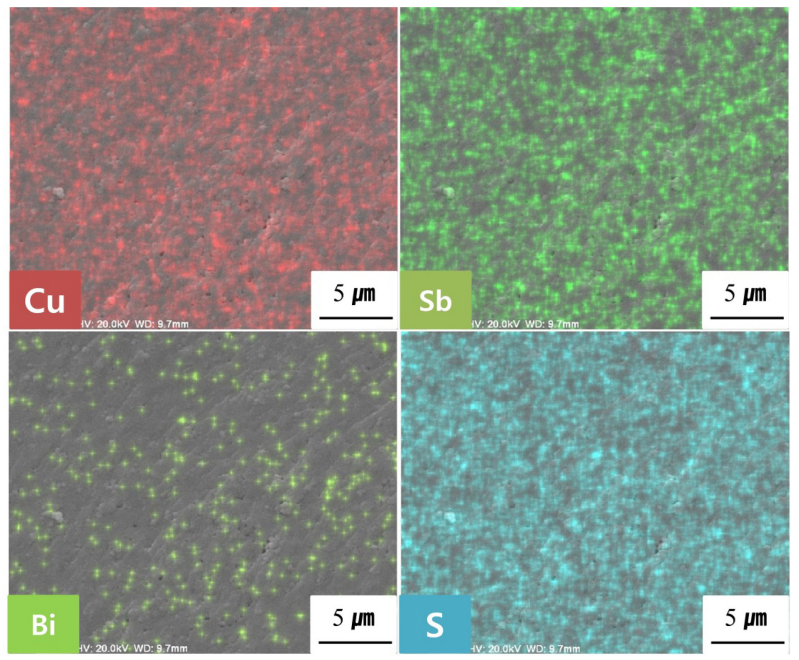

Fig. 3. EDS elemental maps of $\mathrm{Cu}, \mathrm{Sb}, \mathrm{Bi}$, and $\mathrm{S}$ of $\mathrm{Cu}_{12} \mathrm{Sb}_{3.9} \mathrm{Bi}_{0.1} \mathrm{~S}_{13}$.

the experimental method, because the energy levels of $\mathrm{Bi}$ and $\mathrm{S}$ used in the EDS analysis are similar, measurement errors might be high. However, in our previous studies [12-14] on non-doped and doped tetrahedrites prepared by the same MA-HP process, the actual compositions were similar to the nominal compositions.

Figure 4 shows the electrical conductivity of $\mathrm{Cu}_{12} \mathrm{Sb}_{4}$ ${ }_{y} \mathrm{Bi}_{y} \mathrm{~S}_{13}$. The electrical conductivity increased with increasing temperature in all specimens and then decreased at temperatures higher than $623 \mathrm{~K}$. This was thought to be because of the change in conduction behavior with temperature. Tetrahedrites usually show a metallic-tosemiconductor transition, which corresponds to the movement of the Fermi level from inside the valence band to the mid-gap. ${ }^{15}$ The electrical conductivity increased as the amount of $\mathrm{Bi}$ increased. However, it might be unusual to expect that the substitution of $\mathrm{Bi}$ for the $\mathrm{Sb}$ site would not induce changes in the carrier concentration and electrical conductivity because $\mathrm{Bi}$ and $\mathrm{Sb}$ are isovalent. Li et al. [16] 


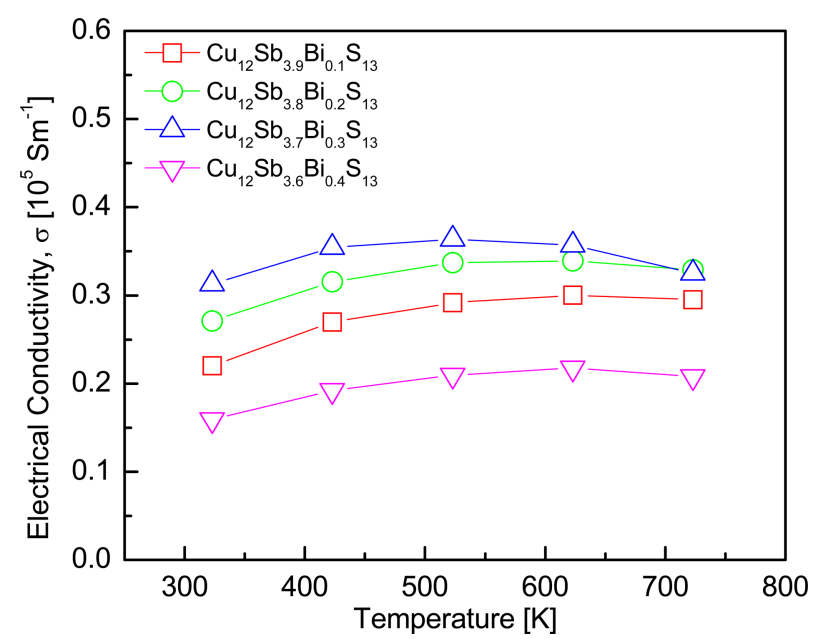

Fig. 4. Temperature dependence of the electrical conductivity of $\mathrm{Cu}_{12} \mathrm{Sb}_{4-y} \mathrm{Bi}_{y} \mathrm{~S}_{13}$.

reported that lattice distortion and point defects $(\mathrm{Cu}$ vacancies) were formed in Bi-doped permingeatites $\mathrm{Cu}_{3} \mathrm{Sb}_{1}$ ${ }_{y} \mathrm{Bi}_{y} \mathrm{Se}_{4}$ because of $\mathrm{Bi}$ substitution, which has a larger radius than $\mathrm{Sb}$. $\mathrm{Cu}$ vacancies acted as acceptors, which was related to the high hole concentration of tetrahedrite $[17,18]$. The specimen with $y=0.4$ showed lower electrical conductivity than $\mathrm{Cu}_{12} \mathrm{Sb}_{3.9} \mathrm{Bi}_{0.1} \mathrm{~S}_{13}$. This was believed to be because of secondary-phase $\mathrm{Cu}_{3} \mathrm{SbS}_{3}$. Kumar et al. [10] reported that the secondary phase can reduce carrier mobility and increase electrical resistivity by charge carrier scattering.

Figure 5 presents the Seebeck coefficient of $\mathrm{Cu}_{12} \mathrm{Sb}_{4}$ ${ }_{y} \mathrm{Bi}_{y} \mathrm{~S}_{13}$. All specimens showed positive values for the Seebeck coefficient. The Seebeck coefficient of a $p$-type semiconductor is expressed as $\alpha=(8 / 3) \pi^{2} k_{B}^{2} m^{*} T e^{-1} h^{-2}(\pi / 3 n)^{2 / 3}$, where $k_{B}$ is the Boltzmann constant, $h$ is the Planck constant, $m^{*}$ is the effective carrier mass, $e$ is the electronic charge, $n$ is the carrier concentration, and $T$ is the absolute temperature [19]. In general, as the temperature increases, the Seebeck coefficient increases, but at a certain temperature or higher, an intrinsic transition occurs and the carrier concentration increases rapidly. Therefore, the contribution to the decrease in the Seebeck coefficient becomes greater than the increase in carrier concentration as the temperature rises, and then the Seebeck coefficient decreases after reaching a peak value. In this study, the temperature dependence of the Seebeck coefficient was similar for all specimens and no intrinsic transition occurred up to $723 \mathrm{~K}$. Because the Seebeck coefficient is inversely related to the carrier concentration, a

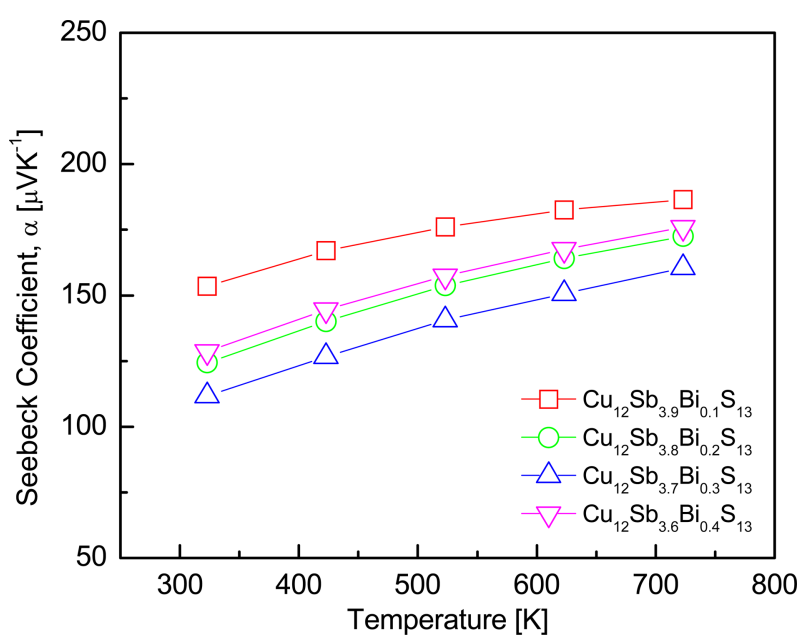

Fig. 5. Temperature dependence of the Seebeck coefficient of $\mathrm{Cu}_{12} \mathrm{Sb}_{4-y} \mathrm{Bi}_{y} \mathrm{~S}_{13}$

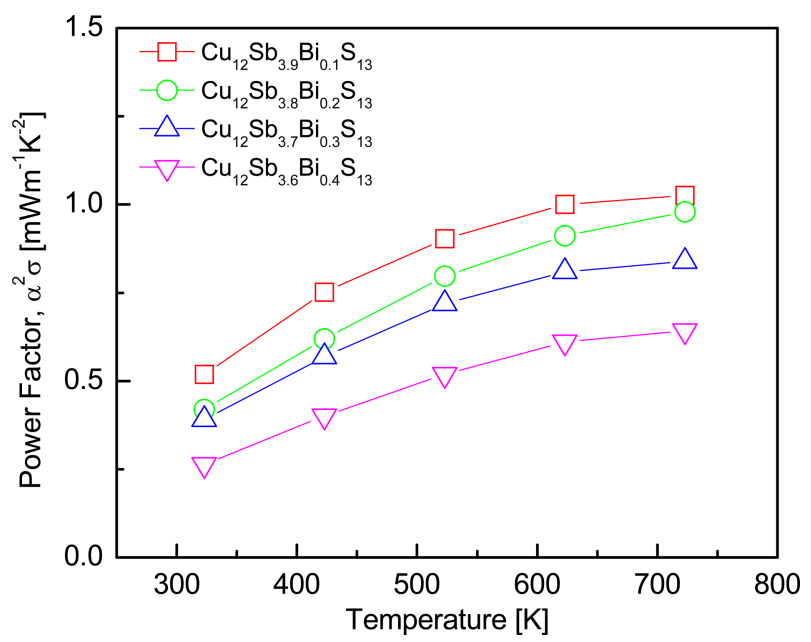

Fig. 6. Temperature dependence of the power factor of $\mathrm{Cu}_{12} \mathrm{Sb}_{4}$ ${ }_{y} \mathrm{Bi}_{y} \mathrm{~S}_{13}$.

higher Seebeck coefficient was obtained at a lower $\mathrm{Bi}$ content. However, the $\mathrm{Cu}_{12} \mathrm{Sb}_{3.6} \mathrm{Bi}_{0.4} \mathrm{~S}_{13}$ specimen showed a higher Seebeck coefficient than the $\mathrm{Cu}_{12} \mathrm{Sb}_{3.7} \mathrm{Bi}_{0.3} \mathrm{~S}_{13}$ specimen, possibly because of the secondary phase, which had the lowest electrical conductivity, as shown in Fig. 4.

Figure 6 shows the power factor of $\mathrm{Cu}_{12} \mathrm{Sb}_{4-y} \mathrm{Bi}_{y} \mathrm{~S}_{13}$. As the temperature increased, the power factor increased. This occurred because of the temperature dependence of the electrical conductivity and the Seebeck coefficient. As the Bi amount increased, the power factor decreased because the decrease in the Seebeck coefficient dominated the increase in the electrical conductivity. Undoped $\mathrm{Cu}_{12} \mathrm{Sb}_{4} \mathrm{~S}_{13}$ showed a maximum $\mathrm{PF}=1.0 \mathrm{mWm}^{-1} \mathrm{~K}^{-2}$ at $723 \mathrm{~K}$ [12], but the power 

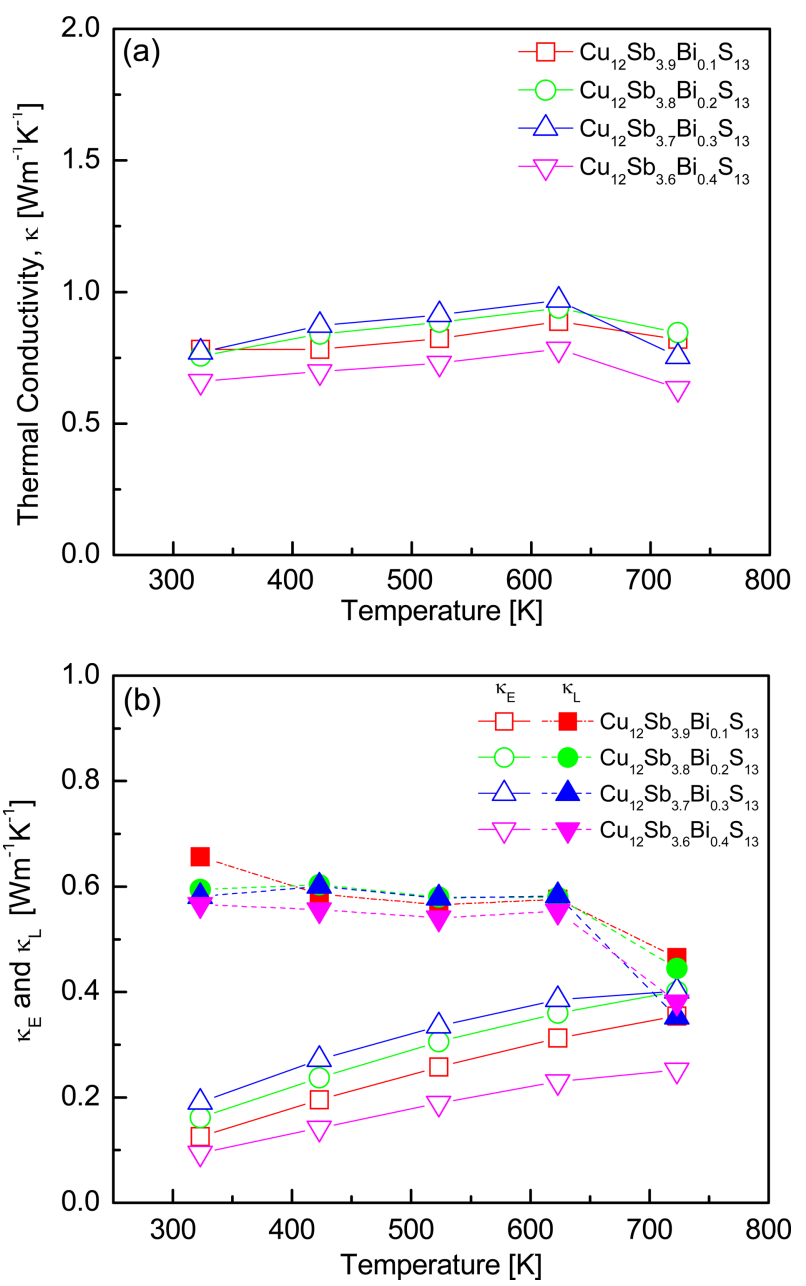

Fig. 7. Temperature dependence of the thermal conductivities of $\mathrm{Cu}_{12} \mathrm{Sb}_{4-y} \mathrm{Bi}_{y} \mathrm{~S}_{13}$ : (a) total thermal conductivity and (b) electronic and lattice thermal conductivities.

factor of $\mathrm{Cu}_{12} \mathrm{Sb}_{3.9} \mathrm{Bi}_{0.1} \mathrm{~S}_{13}$ slightly increased to $\mathrm{PF}=1.02$ $\mathrm{mWm}^{-1} \mathrm{~K}^{-2}$ at $723 \mathrm{~K}$. Kumar et al. [10] obtained $\mathrm{PF}=1.5$ $\mathrm{mWm}{ }^{-1} \mathrm{~K}^{-2}$ at $673 \mathrm{~K}$ for $\mathrm{Cu}_{12} \mathrm{Sb}_{3.8} \mathrm{Bi}_{0.2} \mathrm{~S}_{13}$ because of the increase in the Seebeck coefficient produced by Bi doping. This demonstrates the partial substitution of $\mathrm{Bi}$ for $\mathrm{Sb}$ sites is effective at increasing the power factor of tetrahedrite.

Figure 7 presents the thermal conductivity of $\mathrm{Cu}_{12} \mathrm{Sb}_{4}$. ${ }_{y} \mathrm{Bi}_{y} \mathrm{~S}_{13}$. The thermal conductivity is the sum of the electronic thermal conductivity $\left(\kappa_{E}\right)$ of charge carrier contributions and the lattice thermal conductivity $\left(\kappa_{L}\right)$ of phonon contributions. The electronic thermal conductivity was calculated using the Wiedemann-Franz law ( $\kappa_{E}=L \sigma T, L$ : Lorenz number) [20]. The Lorenz number can be obtained using the relation $L\left[10^{-}\right.$ $\left.{ }^{8} \mathrm{~V}^{2} \mathrm{~K}^{-2}\right]=1.5+\exp (-|\alpha| / 116)$ [21], as shown in Table 1. In
Fig. 7(a), the thermal conductivity slightly increased as the amount of doped $\mathrm{Bi}$ increased in all samples except for that of $y=0.4$. The specimen with $y=0.4$ showed the lowest thermal conductivity of $0.63 \mathrm{Wm}^{-1} \mathrm{~K}^{-1}$ at $723 \mathrm{~K}$, but this was expected to be due to additional phonon scattering by the secondary phase. Kumar et al. [10] achieved the lowest thermal conductivity of $0.98 \mathrm{Wm}^{-1} \mathrm{~K}^{-1}$ at $673 \mathrm{~K}$ for $\mathrm{Cu}_{12} \mathrm{Sb}_{3.6} \mathrm{Bi}_{0.4} \mathrm{~S}_{13}$. The tetrahedrite induces inherently low thermal conductivity, and $\mathrm{Cu}$ atoms lower the lattice thermal conductivity through phonon scattering to bring the lattice thermal conductivity close to the theoretical minimum value [22]. Figure 7(b) shows that the electronic and lattice thermal conductivities were less than $0.40 \mathrm{Wm}^{-1} \mathrm{~K}^{-1}$ and $0.66 \mathrm{Wm}^{-1} \mathrm{~K}^{-1}$, respectively, for all samples over the entire temperature range. The electronic thermal conductivity was in agreement with the tendency of the electrical conductivity to increase with increasing Bi doping content, which was influenced by the increase in carrier concentration.

Figure 8 shows the dimensionless figure of merit $(Z T)$ of $\mathrm{Cu}_{12} \mathrm{Sb}_{4-y} \mathrm{Bi}_{y} \mathrm{~S}_{13}$. The $Z T$ value increased with increasing temperature, and a maximum value of $Z T_{\max }=0.88$ was obtained at $723 \mathrm{~K}$ for $\mathrm{Cu}_{12} \mathrm{Sb}_{3.9} \mathrm{Bi}_{0.1} \mathrm{~S}_{13}$ with a high power factor $\left(1.02 \mathrm{mWm}^{-1} \mathrm{~K}^{-2}\right)$ and low thermal conductivity $(0.81$ $\mathrm{Wm}^{-1} \mathrm{~K}^{-1}$ ). However, the $Z T$ value decreased as the doping level of Bi increased. In the previous study [12], the undoped $\mathrm{Cu}_{12} \mathrm{Sb}_{4} \mathrm{~S}_{13}$ prepared under the same conditions exhibited $Z T_{\max }=0.86$ at $723 \mathrm{~K}$. Barbier et al. [23] obtained $Z T_{\max }=$ 0.60 at $723 \mathrm{~K}$ for $\mathrm{Cu}_{12} \mathrm{Sb}_{4} \mathrm{~S}_{13}$ synthesized by encapsulated

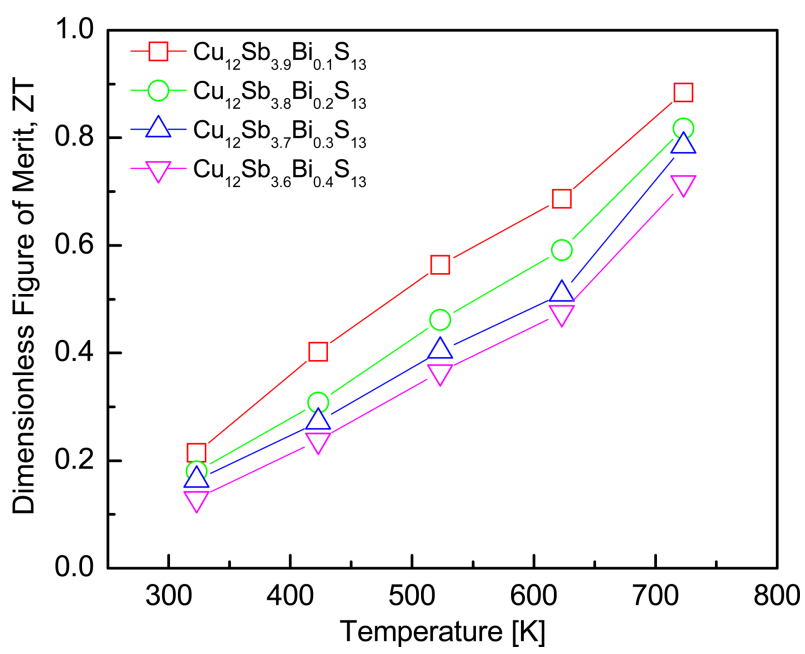

Fig. 8. Dimensionless figure of merit $(Z T)$ of $\mathrm{Cu}_{12} \mathrm{Sb}_{4-y} \mathrm{Bi}_{y} \mathrm{~S}_{13}$. 
melting and spark plasma sintering. Kumar et al. [10] reported $Z T_{\max }=0.84$ at $673 \mathrm{~K}$ for $\mathrm{Cu}_{12} \mathrm{Sb}_{3.8} \mathrm{Bi}_{0.2} \mathrm{~S}_{13}$ fabricated by encapsulated melting and HP. Therefore, the partial substitution of $\mathrm{Bi}$ for $\mathrm{Sb}$ sites by the MA-HP process was successful and effective for improving $Z T$ of tetrahedrite.

\section{CONCLUSION}

Bi-doped tetrahedrites $\mathrm{Cu}_{12} \mathrm{Sb}_{4-y} \mathrm{Bi}_{y} \mathrm{~S}_{13}(y=0.1-0.4)$ were synthesized by MA and sintered by HP. A single tetrahedrite phase was obtained, but specimens with $y \geq 0.3$ had a small amount of the secondary phase (skinnerite). The lattice constant was increased by $\mathrm{Bi}$ doping because $\mathrm{Bi}$ is larger than $\mathrm{Sb}$, and $\mathrm{Bi}$ was confirmed to be substituted for Sb sites. As the $\mathrm{Bi}$ doping level increased, the electrical conductivity increased, but the Seebeck coefficient decreased. This occurred because of the increase in carrier concentration. As a result, a maximum power factor of $1.02 \mathrm{mWm}^{-1} \mathrm{~K}^{-2}$ was achieved at $723 \mathrm{~K}$ for $\mathrm{Cu}_{12} \mathrm{Sb}_{3.9} \mathrm{Bi}_{0.1} \mathrm{~S}_{13}$. All specimens showed very low thermal conductivity below $0.96 \mathrm{Wm}^{-1} \mathrm{~K}^{-1}$ at temperatures in the range of 323 to $723 \mathrm{~K}$. Consequently, $Z T_{\max }=0.88$ was obtained at $723 \mathrm{~K}$ for $\mathrm{Cu}_{12} \mathrm{Sb}_{3.9} \mathrm{Bi}_{0.1} \mathrm{~S}_{13}$, which had a high power factor and no secondary phase.

\section{Acknowledgments}

This study was supported by the Industrial Core Technology Development Program funded by the Ministry of Trade, Industry and Energy (Grant No. 10083640), and by the Basic Science Research Capacity Enhancement Project (National Research Facilities and Equipment Center) through the Korea Basic Science Institute funded by the Ministry of Education (Grant No. 2019R1A6C1010047).

\section{REFERENCES}

1. X. Lu and D. T. Morelli, Phys. Chem. Chem. Phys. 15, 5762 (2013).

2. X. Lu, D. T. Morelli, Y. Xia, F. Zhou, V. Ozolins, H. Chi, X. Zhou, and C. Uher, Adv. Energy Mater. 3, 342 (2013).

3. A. Pfitzner, M. Evain, and V. Petricek, Acta Crystallogr. 53, 337 (1997).

4. Y. Bouyrie, C. Candolfi, S. Pailhès, M. M. Koza, B. Malaman, A. Dauscher, J. Tobola, O. Boisron, L. Saviot, and B. Lenoir, Phys. Chem. Chem. Phys. 17, 19751 (2015).

5. W. Lai, Y. Wang, D. T. Morelli, and X. Lu, Adv. Funct. Mater. 25, 3648 (2015).

6. E. Lara-Curzio, A. F. May, O. Delaire, M. A. McGuire, X. Lu, C. Y. Liu, E. D. Case, and D. T. Morelli, J. Appl. Phys. 115, 193515 (2014).

7. K. Suekuni, K. Tsuruta, T. Ariga, and M. Koyano, Appl. Phys. Exp. 5, 051201 (2012).

8. K. Suekuni, K. Tsuruta, M. Kunii, H. Nishiate, E. Nishibori, S. Maki, M. Ohta, A. Yamamoto, and M. Koyano, J. Appl. Phys. 113, 043712 (2013).

9. H. Subramaniam, B. Manjusha, G. Raghavan, and S. Duraismy, J. Alloy. Compd. 667, 323 (2016).

10. D. S. P. Kumar, R. Chetty, O. E. Femi, K. Chattopadhyay, P. Malar, and R. C. Mallik, J. Electron. Mater. 46, 2616 (2017).

11. Y. Bouyrie, C. Candolfi, V. Ohorodniichuk, B. Malaman, A. Dauscher, J. Tobola, and B. Lenoir, J. Mater. Chem. C 3, 10476 (2015).

12. S. Y. Kim, S. G. Kwak, J. H. Pi, G. E. Lee, and I. H. Kim, J. Electron. Mater. 48, 1857 (2019).

13. S. Y. Kim, G. E. Lee, and I. H. Kim, J. Korean Phys. Soc. 74, 967 (2019).

14. S. G. Kwak, G. E. Lee, and I. H. Kim, Korean J. Met. Mater. 57, 328 (2019).

15. R. Chetty, A. Bali, and R. C. Mallik, J. Mater. Chem. C 3, 12364 (2015).

16. X. Y. Li, D. Li, H. X. Xin, J. Zhang, C. J. Song, and X. Y. Qin, J. Alloy. Compd. 561, 105 (2013).

17. J. Heo, R. Ravichandran, C. F. Reidy, J. Tate, J. F. Wager, and D. A. Keszler, Adv. Energy Mater. 5, 1401506 (2015).

18. T. R. Wei, Y. Qin, T. Deng, Q. Song, B. Jiang, R. Liu, P. Qiu, X. Shi, and L. Chen, Sci. Chin. Mater. 62, 8 (2019).

19. X. Yan, B. Poudel, Y. Ma, W. Liu, G. Joshi, H. Wang, Y. Lan, D. Wang, G. Chen, and Z. Ren, Nano Lett. 10, 3373 (2010).

20. H. Cailat, A. Borshchevsky, and J. P. Fleurial, J. Appl. Phys. 80, 4442 (1996).

21. H. S. Kim, Z. M. Gibbs, Y. Tang, H. Wang, and G. J. Snyder, APL Mater. 3, 041506 (2015).

22. R. Chetty, P. Kumar, G. Rogl, P. Rogl, E. Bauer, H. Michor, S. Suwas, S. Pucjegger, G. Giester, and R. C. Mallik, Phys. Chem. Chem. Phys. 17, 1716 (2015).

23. T. Barbier, P. Lemoine, S. Gascoin, O. I. Lebedev, A. Kaltzoglou, P. Vaqueiro, A. V. Powell, R. I. Smith, and E. Guilmeau, J. Alloy. Compd. 634, 253 (2015). 